ارزيابى شاخص خشكسالى جديد SPDI (Standardized Palmer Drought Index)

\author{
استان جهارمحال و بختيارى \\ فرنوش صنيع ثالث"، سعيد سلطانى و رضا مدرس'

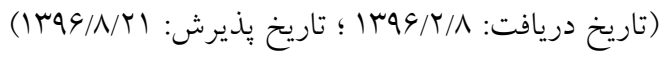

جكيده

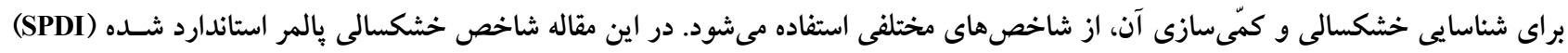

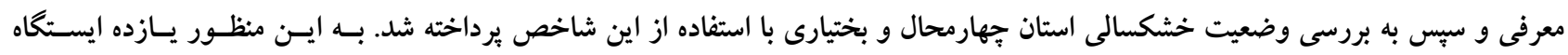

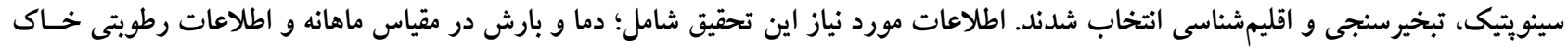

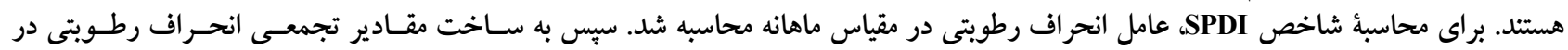

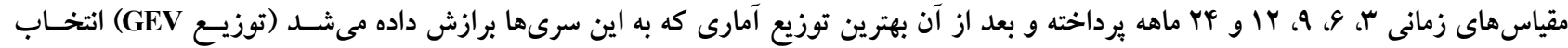

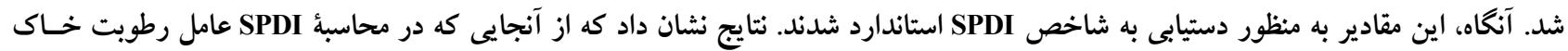

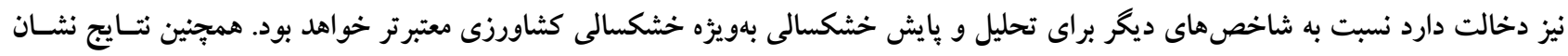

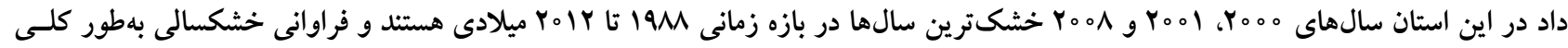
در نيمه غربى استان بيشتر مشاهده مي هود.

وازٔهاى كليدى: شاخص بالمر استاندارد شده، بايش خشكسالى، شاخص بارش استاندارد شده، رطويت خاك، استان جهارمحال و بختيارى 
كسترداى از آن در سطح جهان مىشد و به يك استاندارد براى

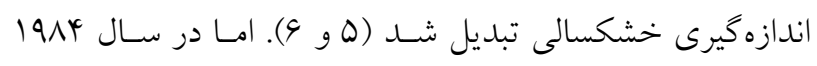

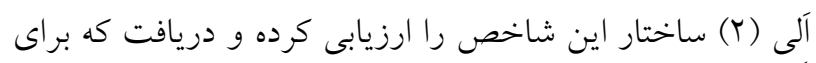

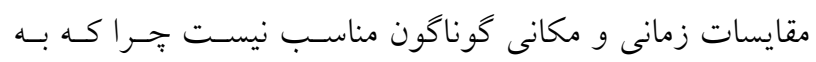

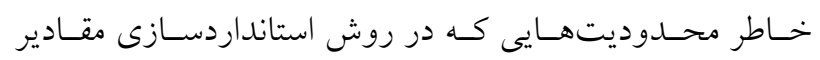
PDSI

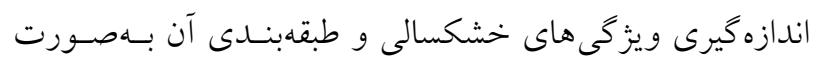

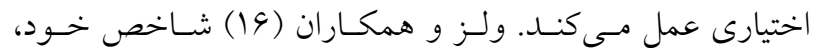

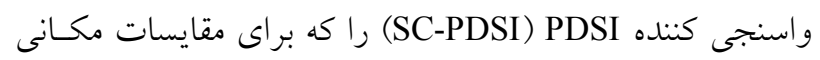

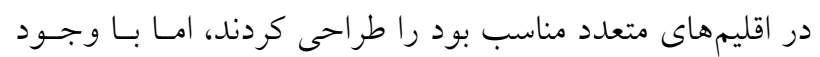

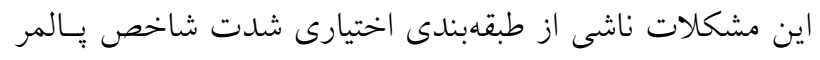
حل نشده باقى ماند و محاسبات همجنان وابسته بـهـ موقعيـت و

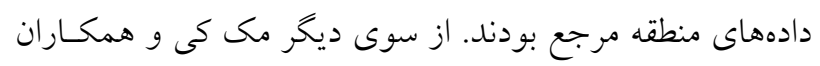

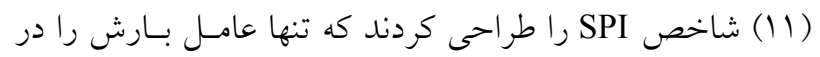

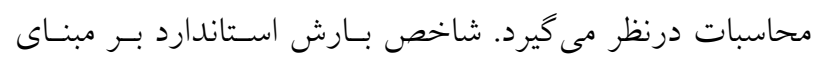

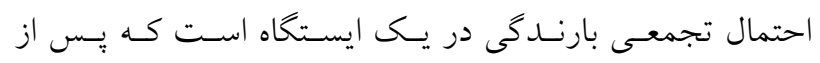

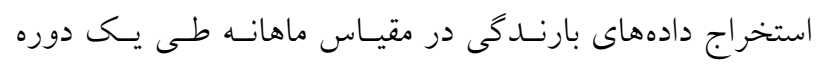

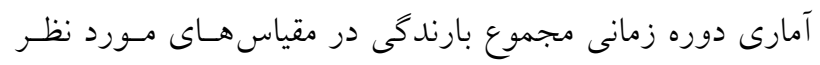

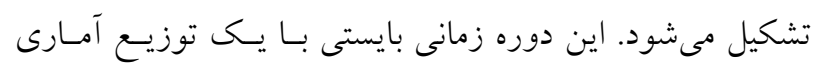

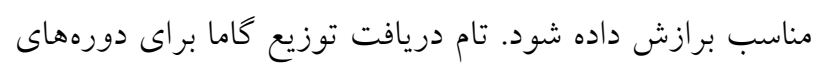

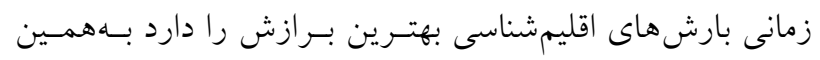

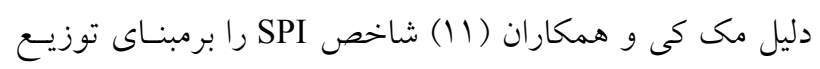

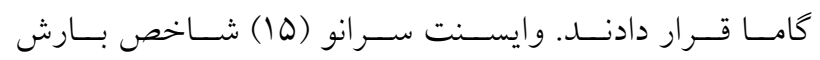

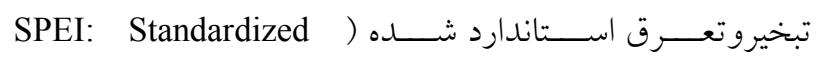
Precipitation Evapotranspiration Index در شاخص ييشنهادى آنها از تفاضـل بـارش و تبخيـر و تعـرق

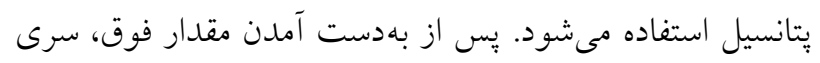

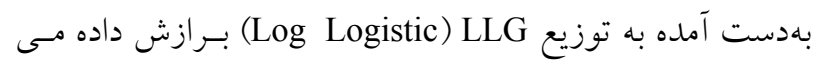

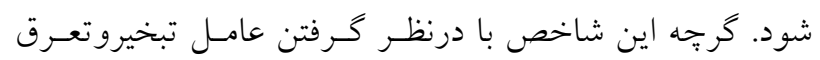

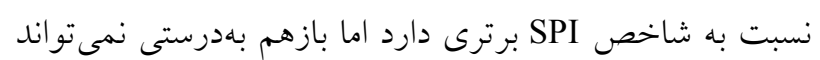

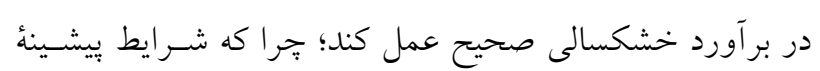

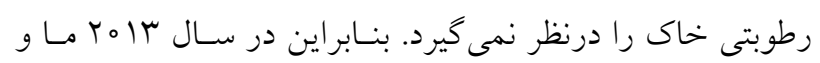

بديده خشكسالى از جمله حوادثى است كه بخشه هاى زيادى از

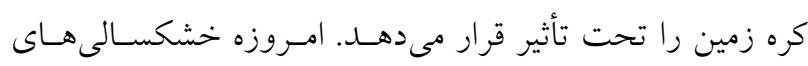

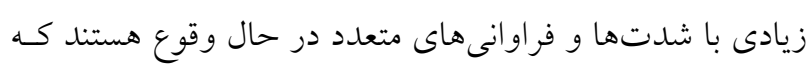

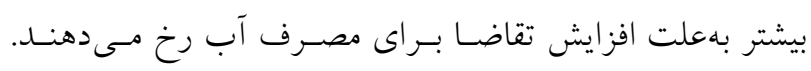

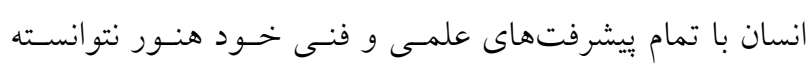

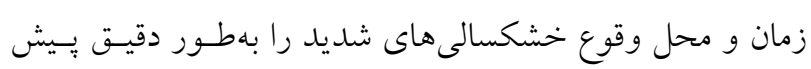

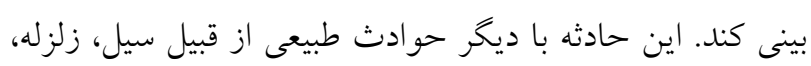

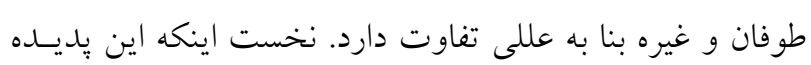

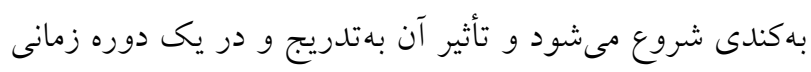

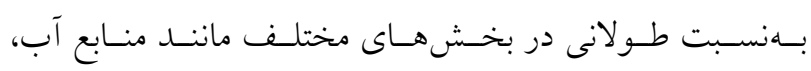

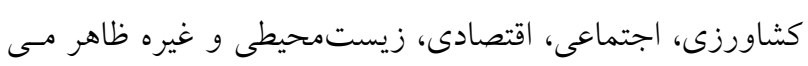

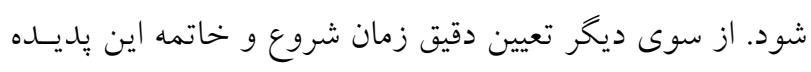

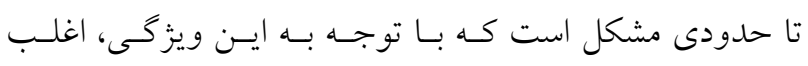

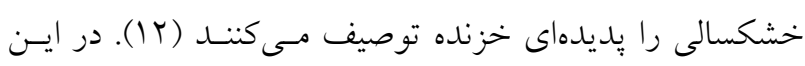

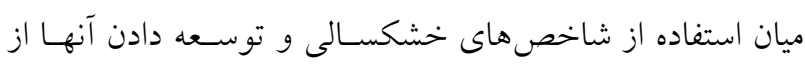

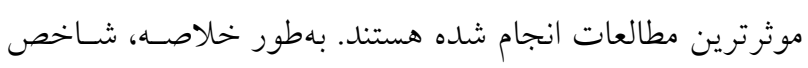

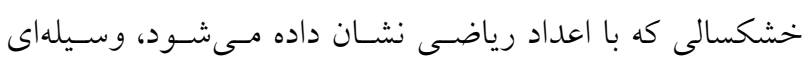

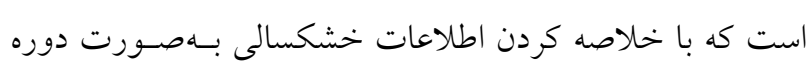

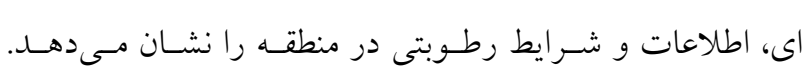

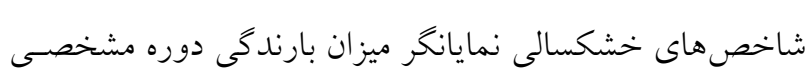

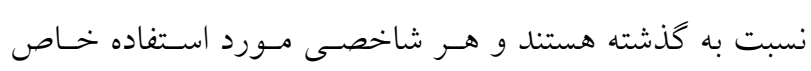

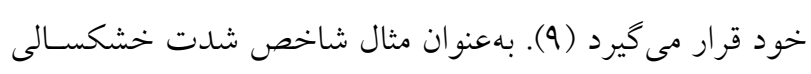

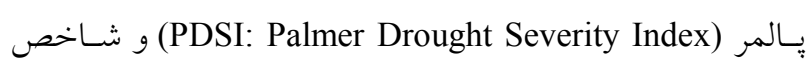
(SPI: Standardized Precipitation بـارش استاندارد شــــ دو شـاخص برجسـته در امـر كمسىســازى بديــــ Index ) خشكسالى هستند. شاخص PDSI در سال 1990 توسط بـ بـالمر

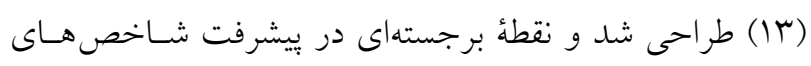

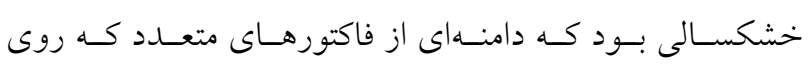

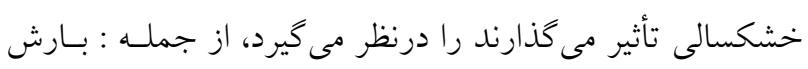

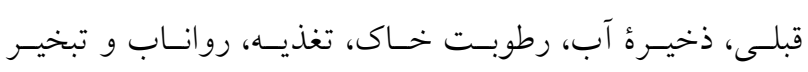

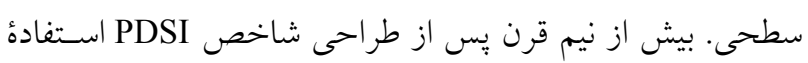


مساحت كشور را دربرمى گيرد. از نظر موقعيت جغرافيايى بين

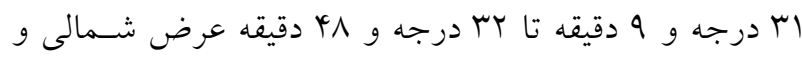

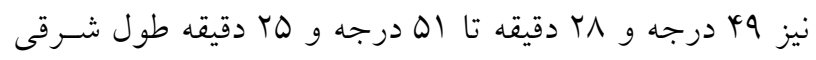

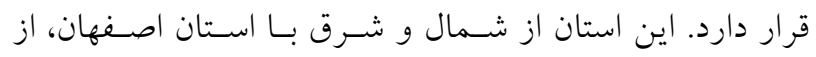

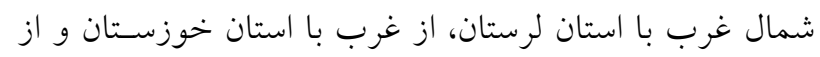

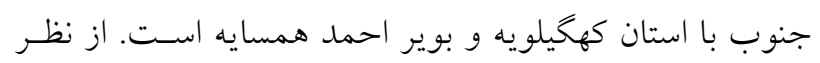

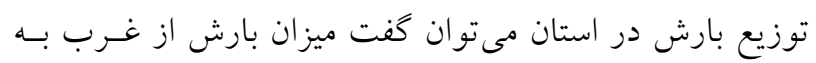

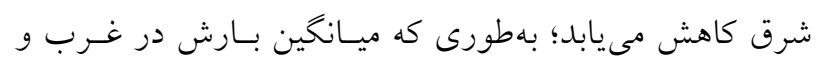

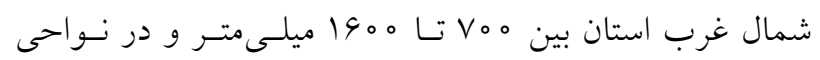

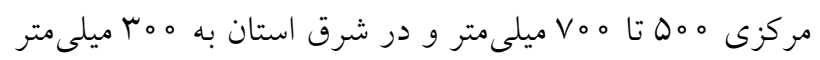

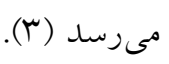

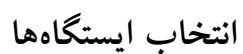

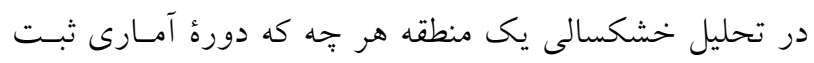

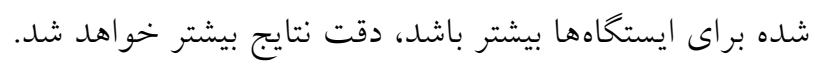

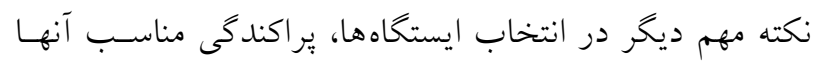

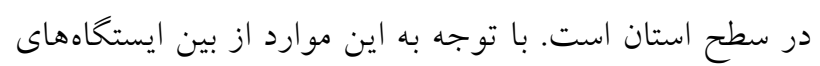

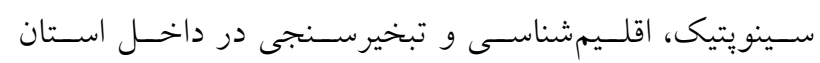

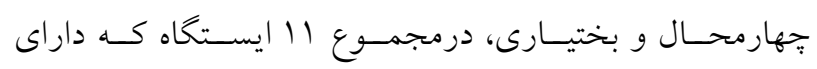

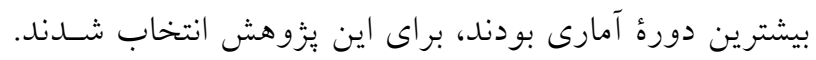

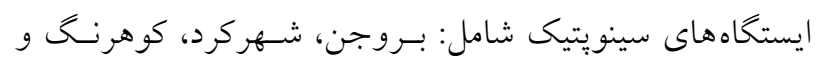

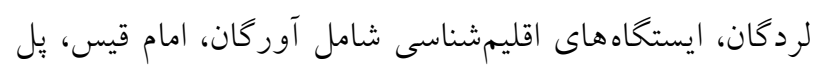

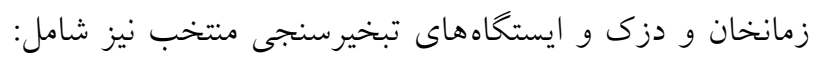

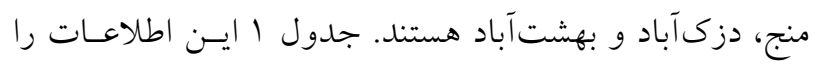

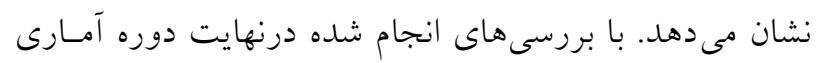

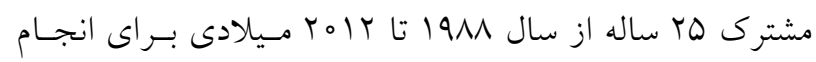

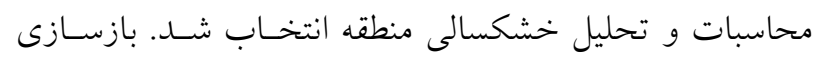

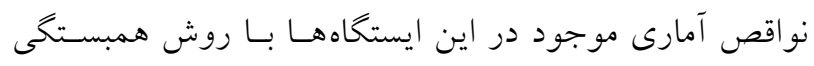

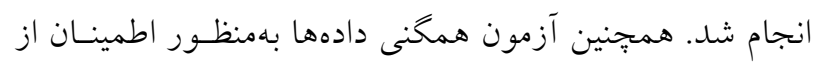

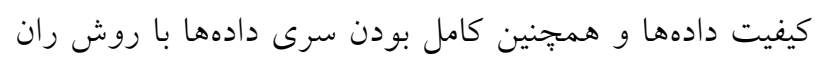
تست انجام شد كه دادهاى تمامى ايستخاهها در سطح اطمينان

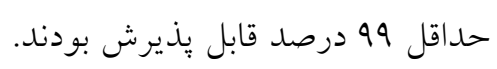

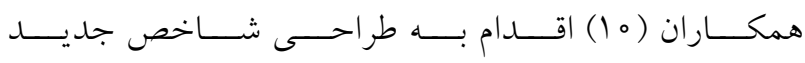
SPDI (Standardized Palmer Drought Index) آن شاخص پِالمر را استاندارد كــده و فراينـــ محاسـبه مشـابه

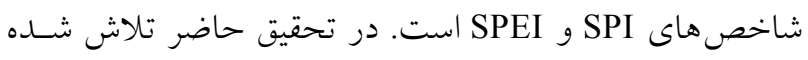

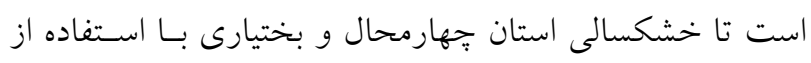

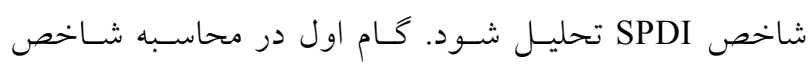

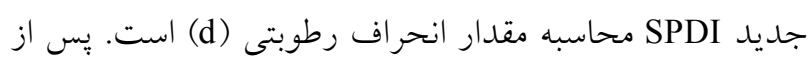

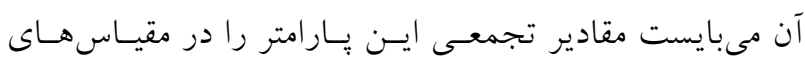

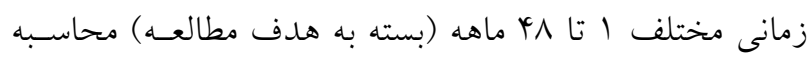

كام بعدى انتخاب بهترين تابع توزيع تجمعس F(x)

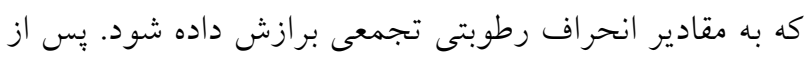

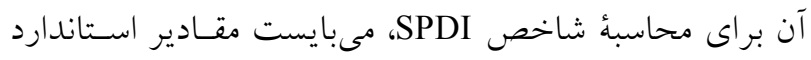

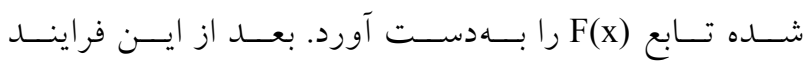

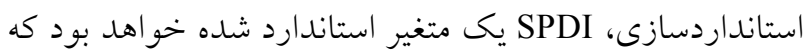

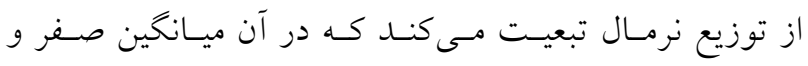

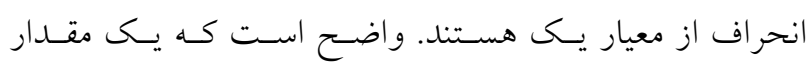

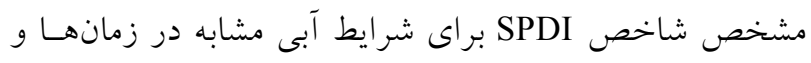

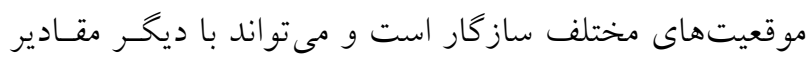
SPDI

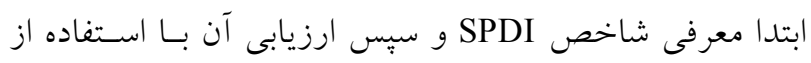

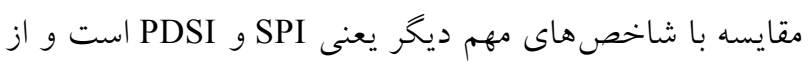

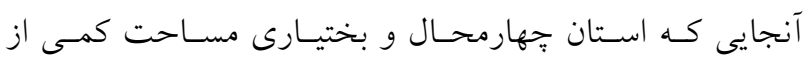

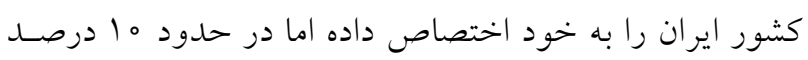

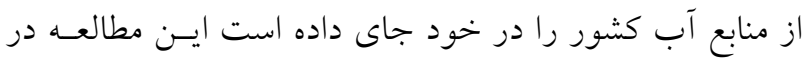

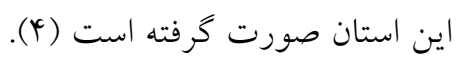

مواد و روشها معرفى منطقه مورد مطالعه

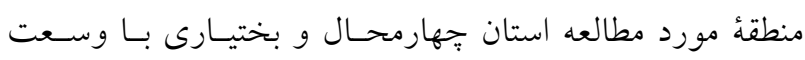

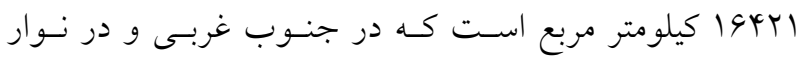

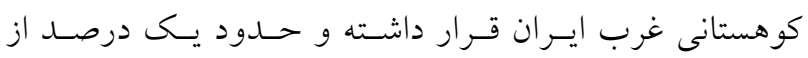


جدول ا. موقعيت ايستخاهاى استفاده شده در تحقيق

\begin{tabular}{|c|c|c|c|c|c|c|}
\hline $\begin{array}{l}\text { ارتفاع } \\
\text { (متر) }\end{array}$ & متوسط بارش & 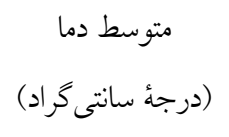 & عرض جغرافيايى & طول جغرافيايى & نوع ايستخاه & نام ايستگاه \\
\hline YYIO & DIN/DG & $10 / 0 \mathrm{~V}$ & ا ا درجه و OH دقيقه & مه درجه و QV دقيقه & اقليمشناسى & آوروكان \\
\hline TYAD & $9 \circ \wedge / 14$ & $11 / 01$ & اب درجه و Q & اله درجه و N| دقيقه & اقليمشناسى & امام قيس \\
\hline rrgo & rQY/IY & $\mid r / 4 T$ & آس درجه و هQ دقيقه & |ه درجه و 11 دقيقه & سينويتيك & بروجن \\
\hline $1 V \cdot 0$ & $911 / 91$ & $14 / 40$ & זس درجه و ا دقيقه & DD درجه و rV دقيقه & تبخيرسنجى & بهشت آباد \\
\hline iMMr & (T/NT & $\mid r / T \Lambda$ & rr درجه و مr دقيقه & اله درجه و OY دقيقه & اقليمشناسى & يل زمانخان \\
\hline$r \circ \Delta Y$ & YQT/QS & $11 / T r$ & rr درجه و ه دقيقه & 0ه درجه و Q D دقيقه & اقليمشناسى & دزى \\
\hline rral & $\Lambda F N / q$ & $10 / 0$ & rr درجه و 10 دقيقه & مه درجه و 19 دقيقه & تبخيرسنجى & 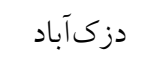 \\
\hline$r \circ \Delta \circ$ & $r Y q / 41$ & $11 / 9$ & rr درجه و VI دقيقه & مه درجه و اه دقيقه & سينويتيك & شهركرد \\
\hline rmso & IrVI/Ar & $9 / \wedge \Delta$ & r درجه و rV دقيقه & ه Q درجه و م دقيقه & سينويتيك & كوهرنخ \\
\hline 1911 & $\Delta Q V / I V$ & $19 / 4$ & اب درجه و مب دقيقه & 00 درجه و 00 دقيقه & سينويتيك & ل لردمان \\
\hline lyOr & $\Delta \wedge q / 9 Y$ & $1 V / 9$ & آr درجه و rr دقيقه & 0ه درجه و رץ دقيقه & تبخير سنجى & منج \\
\hline
\end{tabular}

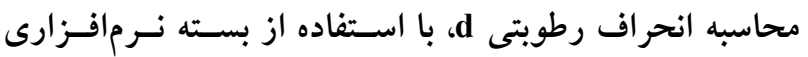

شاخص PDSI Pآ

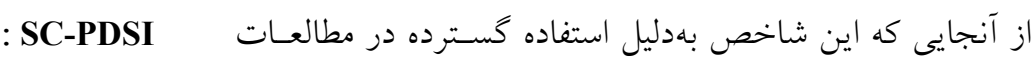

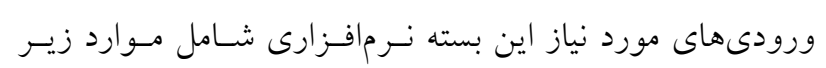

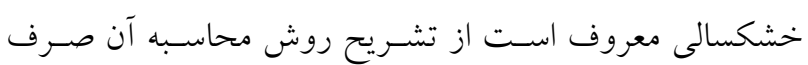
است: آمار مربوط بـهـ بـارش ايستخاه درو مقيـاس ماهانـه، آمـار

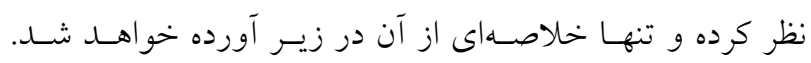

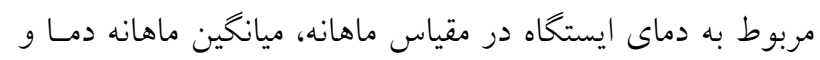

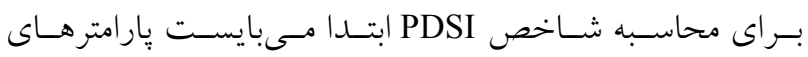
يارامتر. اين جهار مورد مىبايست با فرمـت (Notepad) مطـابق تبخيروتعرق، اتلاف رطوبت، تغذيه رطوبت و رواناب در حالت

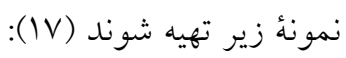

$\begin{array}{lllllll}1989 & -0.516 & -1.125 & 3.785 & 9.526 & 13.300 & 17.000\end{array}$

$\begin{array}{lllllll}1990 & -3.000 & 0.000 & 4.000 & 9.000 & 15.000 & 19.000\end{array}$ $\begin{array}{lllllll}1991 & -1.000 & 0.000 & 5.000 & 10.000 & 13.000 & 18.000\end{array}$ $\begin{array}{llllll}20.513 & 18.930 & 15.993 & 12.126 & 7.030 & 2.433\end{array}$

$\begin{array}{llllll}20.000 & 21.000 & 18.000 & 12.000 & 8.000 & 3.000\end{array}$

$\begin{array}{llllll}21.000 & 21.000 & 18.000 & 10.000 & 7.000 & 2.000\end{array}$

فايلى كه با نام بارامتر ساخته مىشود شامل دو عدد است؛ عــد

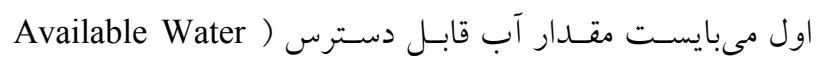
(Capacity

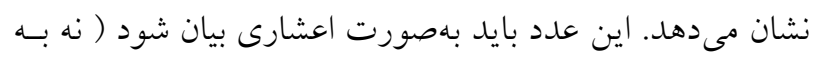

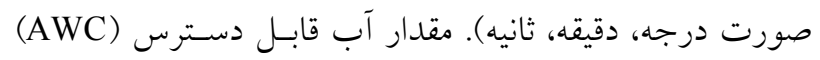

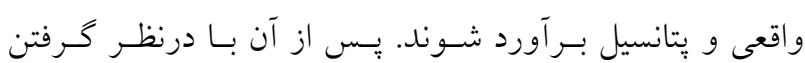
ضرايب مربوطه بارندگى مناسب از نظـر اقليمسى بــراى شـرايط CAFEC : Climatically Appropriate For Existing ( موجسود (Conditions Precipitation داده در منطقه مقدار انحر اف رطوبتى (d) محاسبه مىشـود. لازم

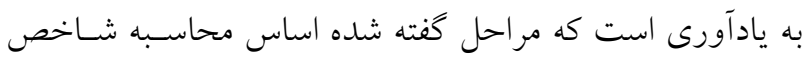
نيز هستند. در ادامسه محاسـبه شـاخص SPDI

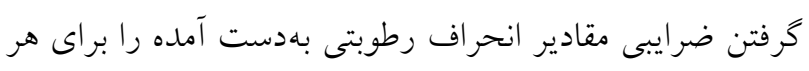

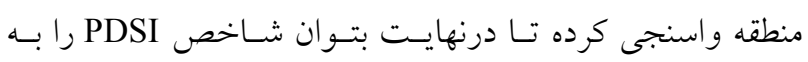
دست آورد. 
مقادير تجمعى در مقياسهاى زمانى مختلف تهيـه شــه و وارد مرحلة استانداردسازى مى شود.

انتخاب بهترين توزيع آمـارى بـه مقــادير تجمعسى انحـراف

dطوبتى

براى محاسبة شاخص SPDI، بايد يكى توزيع آمارى مناسب كـه

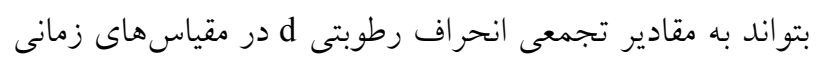
مختلف، بهخوبى برازش داده شود، انتخاب شود.

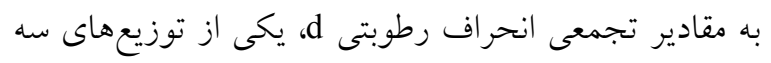

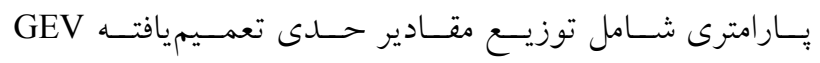

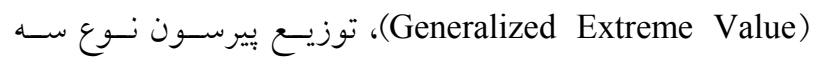
(Pearson type III)

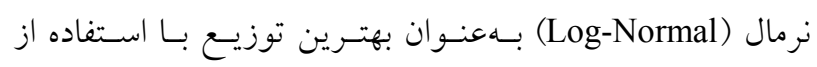

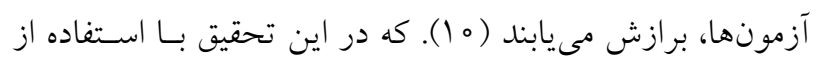

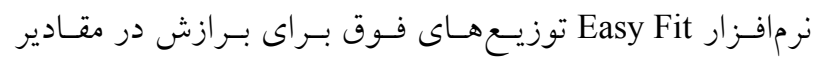

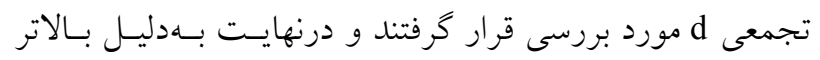

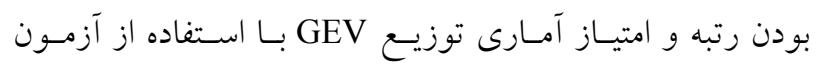

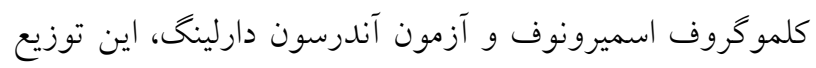
به بعنوان بهترين توزيع براى برازش به مقـادير تجمعسى انحـراف

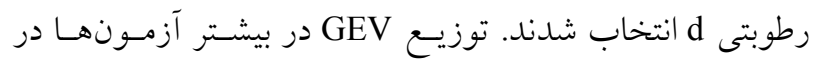

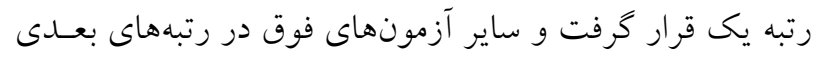

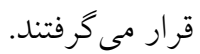
توزيع مقدار تابع تجمعى توزيع GEV بهصورت زير فر فر است : $\mathrm{F}(\mathrm{x})= \begin{cases}\exp \left(1-(1+\mathrm{kz})^{-1 / \mathrm{k}}\right) & \mathrm{k} \neq 0 \\ \exp (-\exp (-\mathrm{z})) & \mathrm{k}=0\end{cases}$

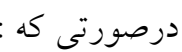

$\mathrm{z} \equiv \frac{\mathrm{x}-\mu}{\sigma}$

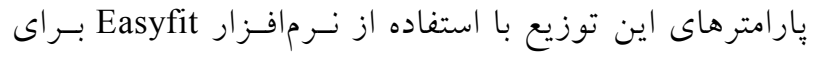

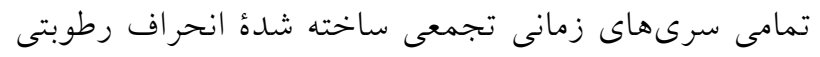

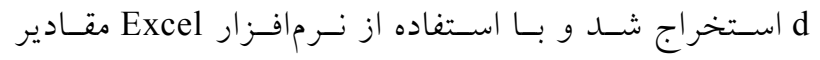
انحراف رطوبتى در سطوح احتمال مختلـف در ايسن توزيـع بر آورد شد.
در محاســبهُ PDSI بسـيار حسائز اهميـت اســت، بنـابراين بايد دقت شود كه اطلاعات صحيح در اين مورد استفاده شـود.

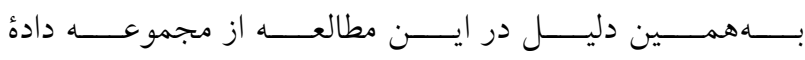
USDA' s STATSGO بافت خاك و ماده آلى توسط مجموعة فوق محاسبه شده اسـت

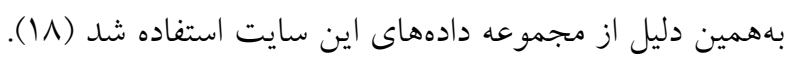

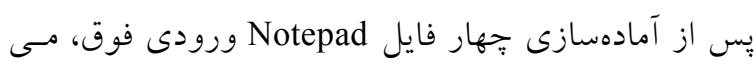

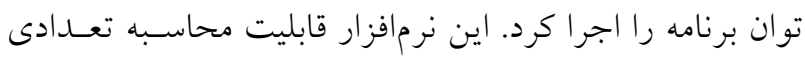

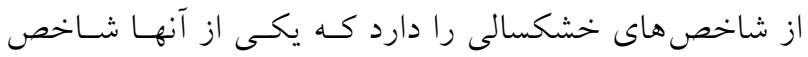
PDSI

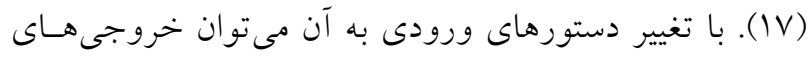

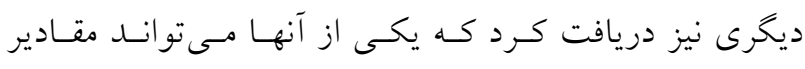

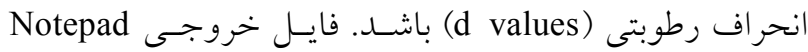

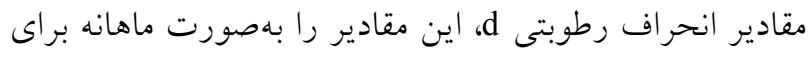

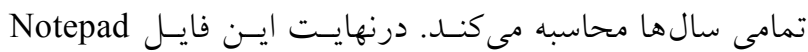

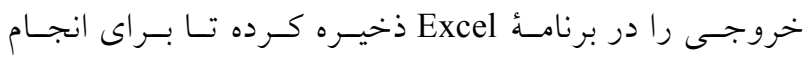

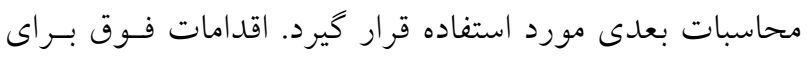

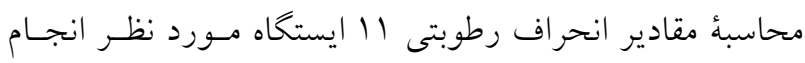
كرفت.

\section{d محاسبه مقادير تجمعى انحراف رطوبتى}

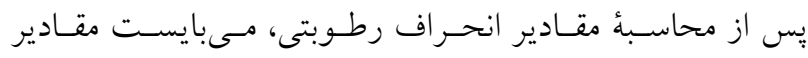

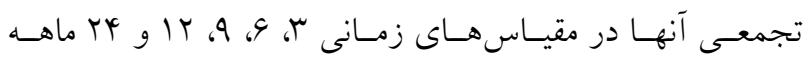

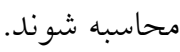

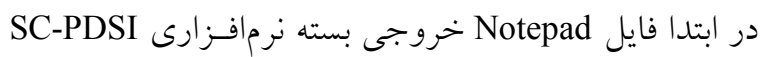

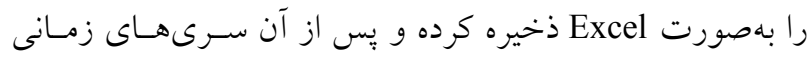

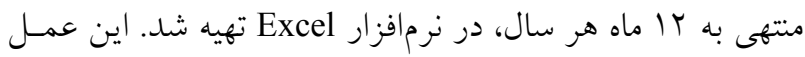

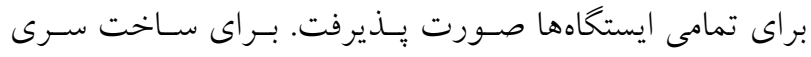

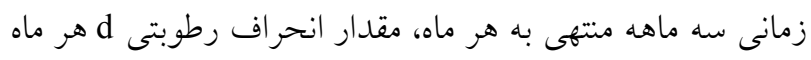

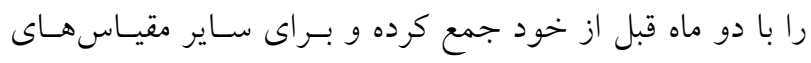

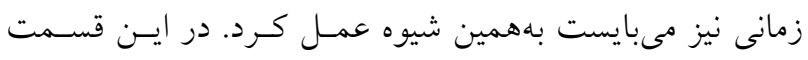

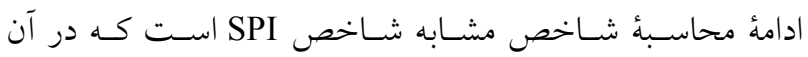


جدول r. شاخص SPDI در مقياس Y I ماهه منتهى به ماه دسامبر ايستخاه شهر كرد

\begin{tabular}{|c|c|c|c|}
\hline SPDI & مقدار در توزيع GEV & مقدار تجمعى انحراف رطوبتى & 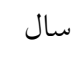 \\
\hline$-0 / 94$ & $0 / 49$ & $-1 / \Lambda \Lambda$ & 1911 \\
\hline$-0 / 19$ & OMt & $-0 / 14$ & 1919 \\
\hline$-1 / 1 \mu$ &.$/ 1 \mathrm{r}$ & -r/N & $\begin{array}{l}1990 \\
\vdots\end{array}$ \\
\hline$-0 / T V$ & $0 /, q$ & $-0 / \uparrow \wedge$ & $r 011$ \\
\hline $0 / 4 V$ & $0 / 91$ & $r / 90$ & $r_{0} \mid r$ \\
\hline
\end{tabular}

در جدول r نمونهاى از محاسبة شـاخص SPDI در مقيـاس 1 I

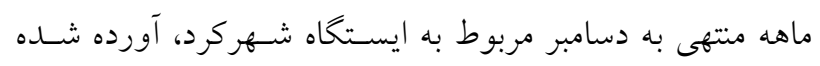

\section{SPDI نتايج محاسبه شاخص} با استفاده از روشهاى ذكر شده در ايسن مقالـه شـاخص SPDI

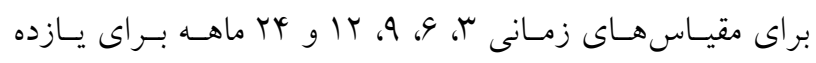

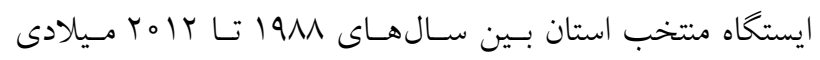
محاسبه شد. براى ارزيابى، اين شاخص بـا شـاخص SC-PDSI مقايسه شد. نتايج نشان داد كه در بيشتر ايستخاهها الكوى تغييرات زمانى هردو شاخص تشابه زيادى دارد. بهعنوان مثال شكل ا شاخص ئج

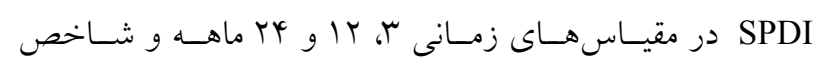
را براى ايستخاه شهر كرد و كوهرنخ نشان مى دهنـد. SC-PDSI همانطور كه مشاهده مى شود خشكسالىهاى شديد در سالهاى

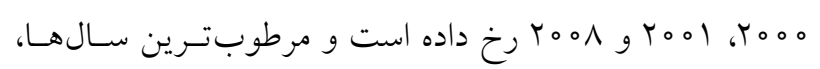

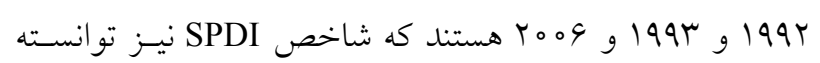
اين وقايع را همانند شاخص SC-PDSI بهخـوبى نشـان دهــ و در واقع شاخص SPDI همبستخى بالايى با شـاخص SC-PDSI دارد. نتايج بيانخر آن اسـت كـه شـاخص SPDI بـهدليـل اينكـه شاخصى استاندارد است، حساسيت بيشترى به تغييرات شـرايط

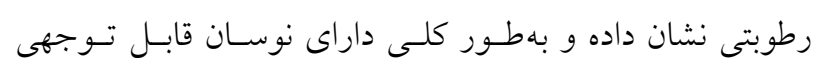

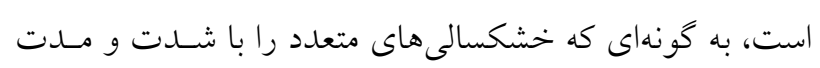

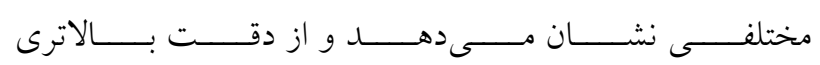

تبديل هم احتمال مقـادير تجمعسى در توزيـع GEV بـه نرمـال |ستاندارد براى استانداردسازى سـرىهـاى مقـادير تجمعسى انحـراف رطوبتى در توزيع GEV بايستى آنها را به مقادير هم احتمـال در

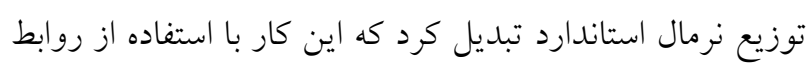
زير طبق روش آبرامويتز و استو گان انجام شود (1): SPDI $=\mathrm{W}-\frac{\mathrm{a}_{\mathrm{o}}+\mathrm{a}_{1} \mathrm{~W}+\mathrm{a}_{2} \mathrm{~W}^{2}}{1+\mathrm{b}_{1} \mathrm{~W}+\mathrm{b}_{2} \mathrm{~W}^{2}+\mathrm{b}_{3} \mathrm{w}^{3}}$

where $\mathrm{W}=\sqrt{-2 \operatorname{In}(\mathrm{p})}$ for $\mathrm{p} \leq 0.5$, and $\mathrm{p}=1-\mathrm{F}(\mathrm{x})$

$\mathrm{a}_{\mathrm{o}}=2.515517, \mathrm{a}_{1}=0.802853, \mathrm{a}_{2}=0.010328$,

$b_{1}=1.432788 \quad b_{2}=0.189269$ and $b_{3}=0.001308$.

براى مقادير بيش از ه/ه از مقدار p - 1 استفاده مىشود و مقدار

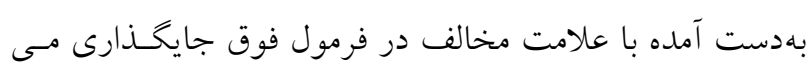
شود. استانداردسازى مقادير تجمعسى توزيـع GEV در نــرم افـزار NORM.S.INV براساس روابط فوق با استفاده از دستور Excel انجام كرفت كه خروجى آن همان شاخص SPDI برست است.

\section{نتايج و بحث}

يس از محاسبه مقادير تجمعى انحراف رطوبتى، با استفاده از نرم

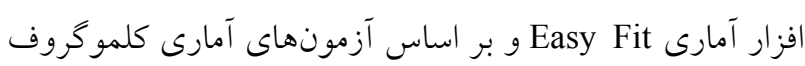
اسميرونوف و آندرسون دارلينخ توزيع GEV بهعنـوان بهتـرين توزيع انتخاب شد. 


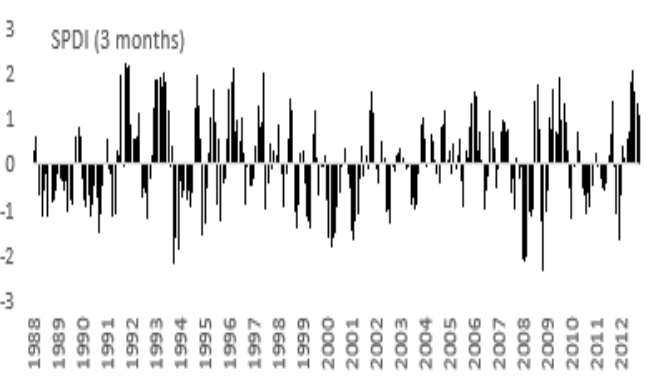

SPDI (12 months)

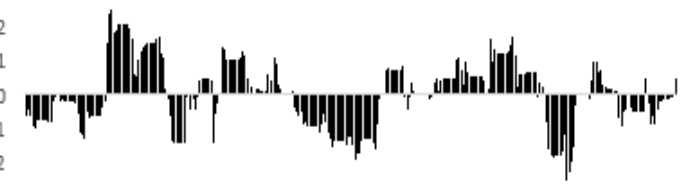

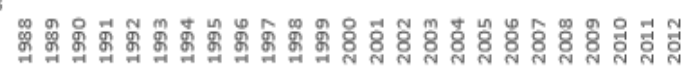

SPDI (24 months)

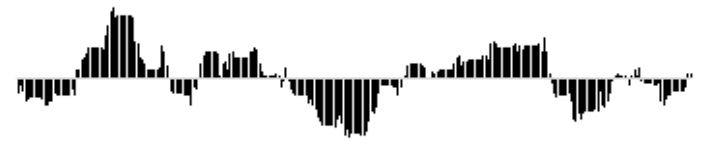

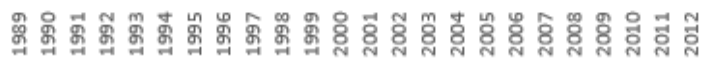

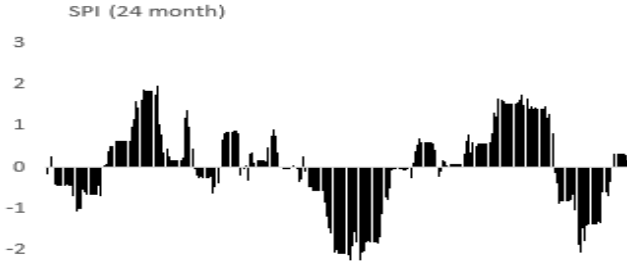

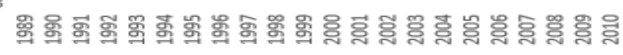

PDSI

$\left.\right|_{2} ^{4}$

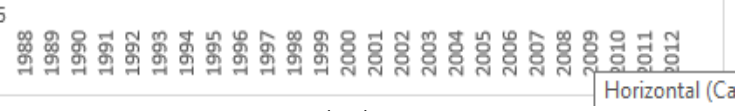

(ب)
SPDI (3 months)

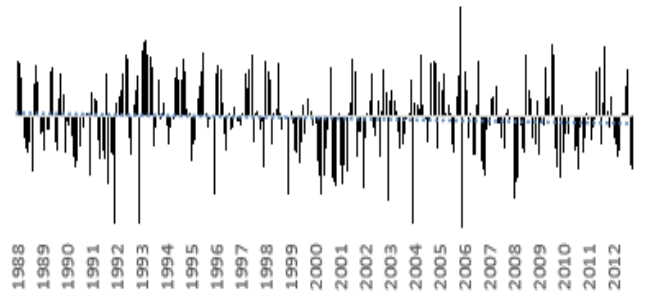

SPDI 12 (months)

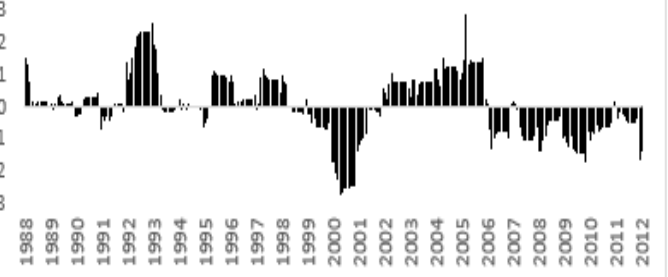

SPDI 24 (months)

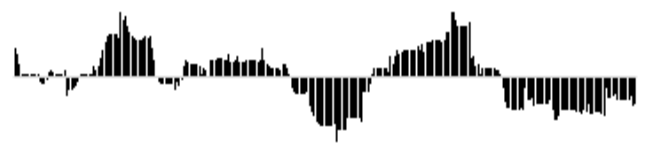

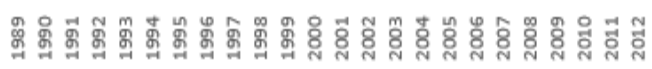

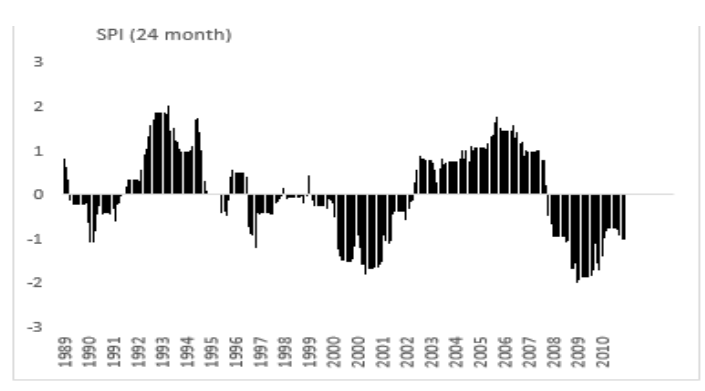

PDSI

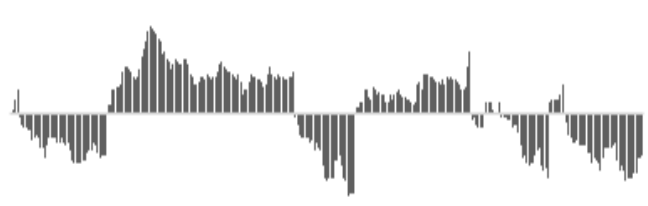

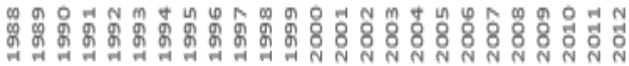

(الف)

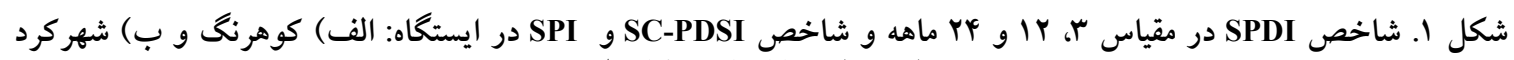

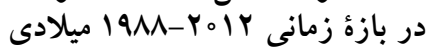


نقشه هاى بهندبندى خشكسالى گستره فراوانى نسبى خشكسالى در استان جهارمحال و بختيارى خُش

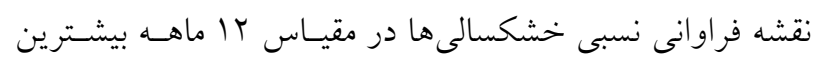

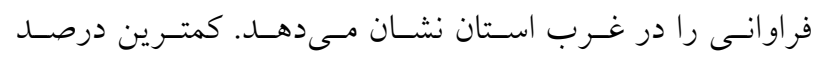

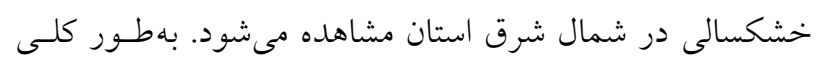

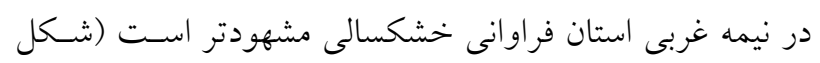

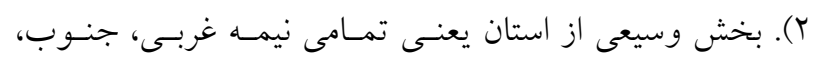

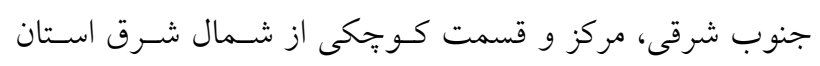

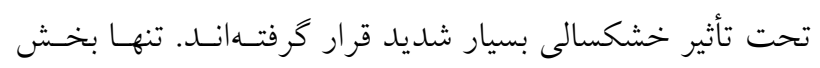

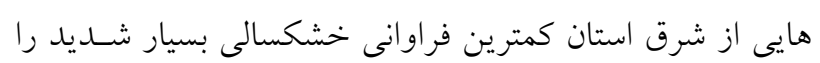

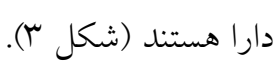

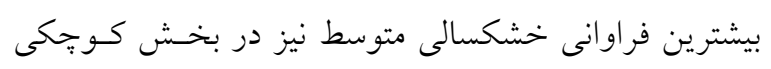
از شمال غرب و نيز بخشهايى از شرق استان مشاهده مىشود.

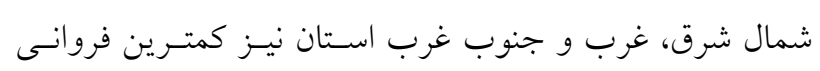

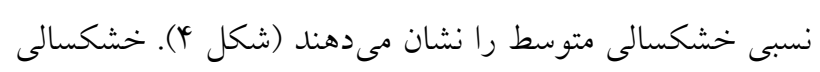

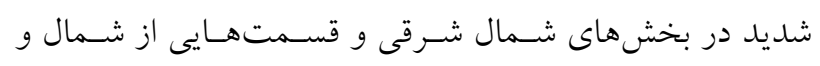

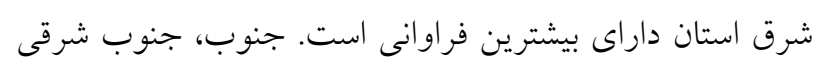

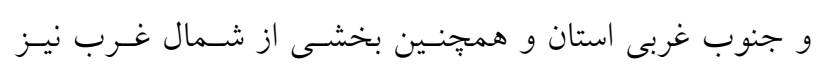
كمترين فروانى را دارند (شكل ه ه).

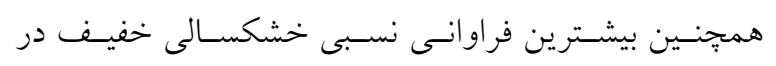

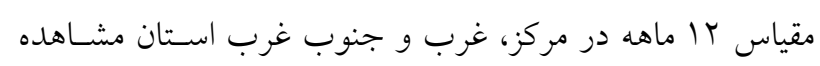

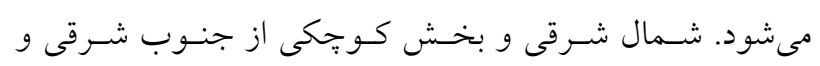

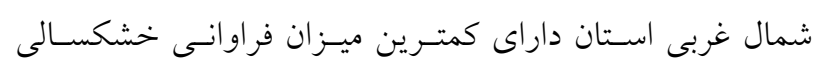
هستند (شكل 9).

\section{نتيجه گيرى}

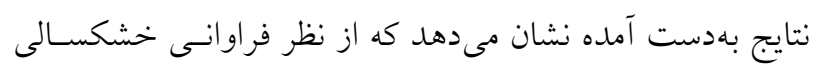

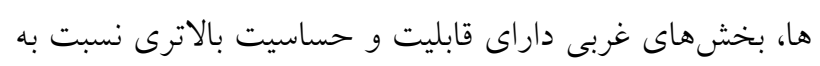

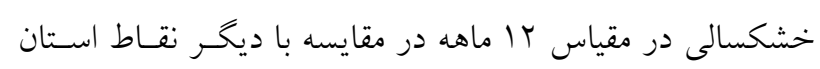

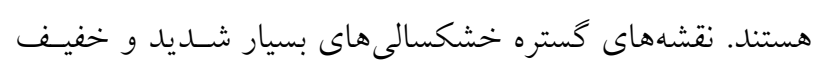
بيشترين فراوانى را در نيمه غربى استان دارند. نيمه شرقى استان

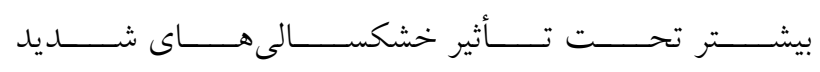

برخوردار است. بههمين دليـل ايسن شـاخص از كـارايى بـالايى

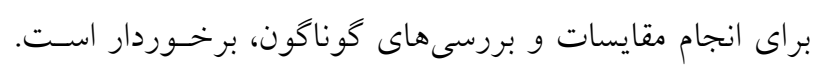

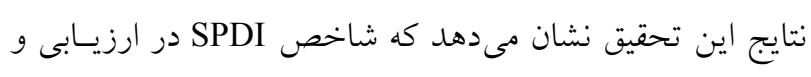

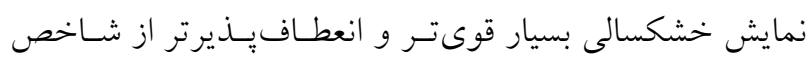

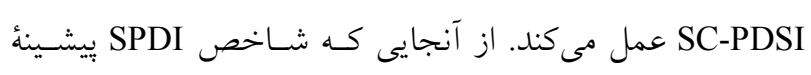

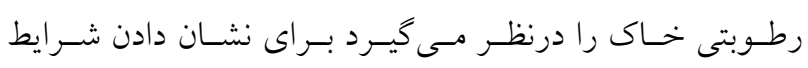

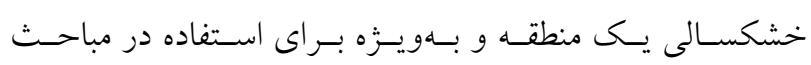

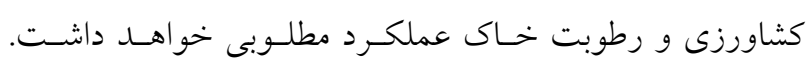

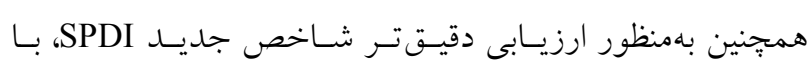

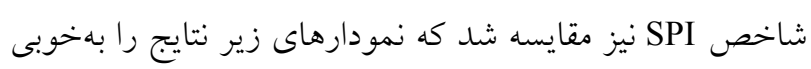

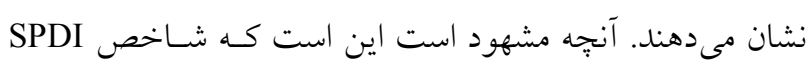

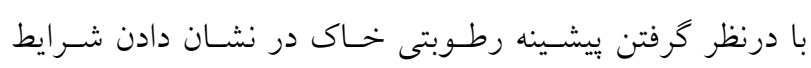

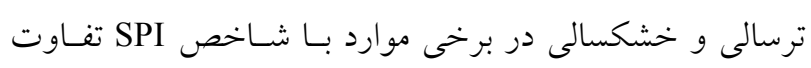

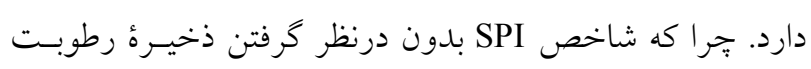

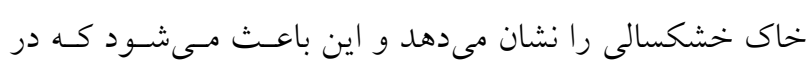

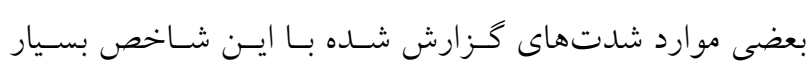

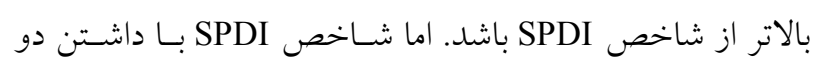

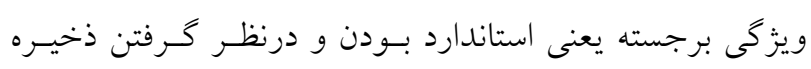

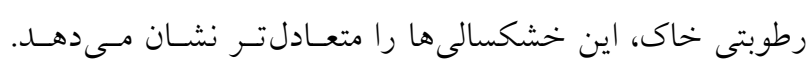

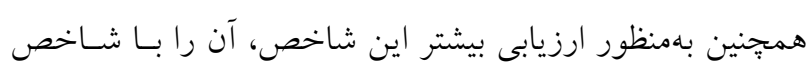

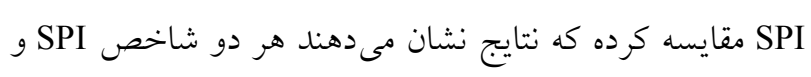
SPDI

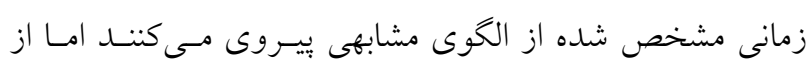

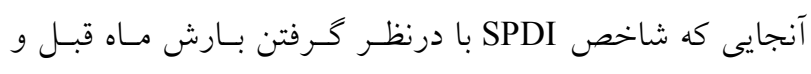

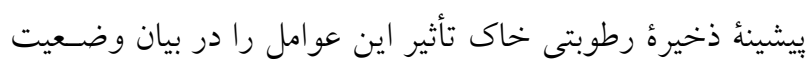

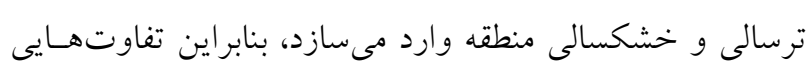

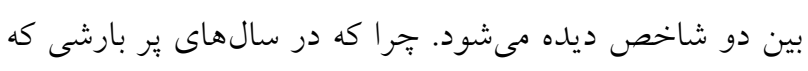

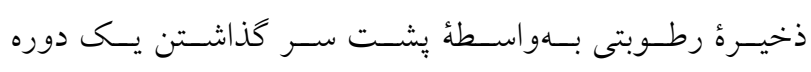

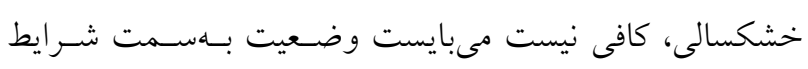

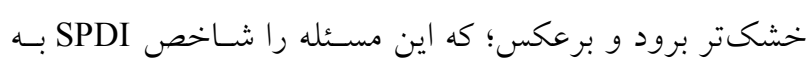

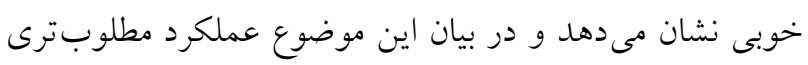
نسبت به شاخص SPI داشته است. 

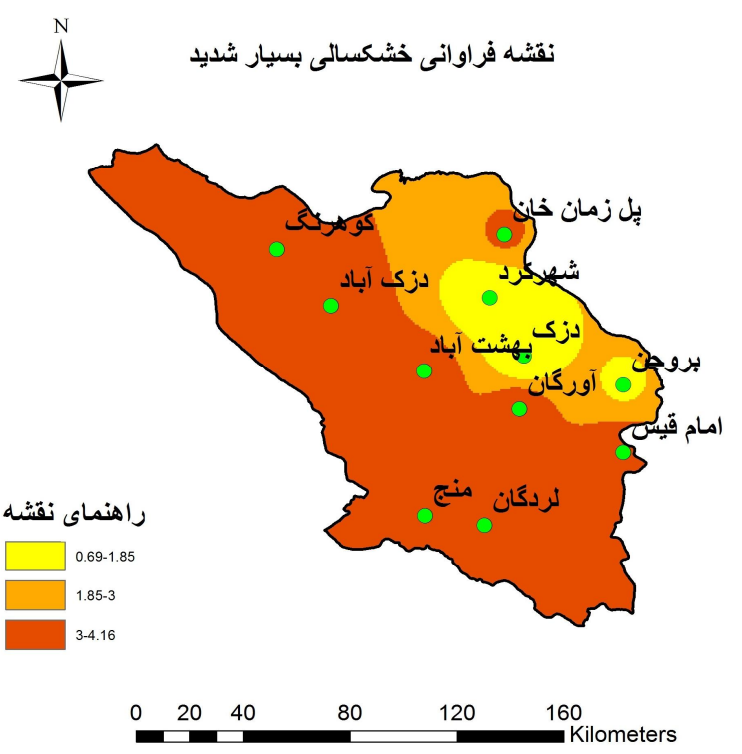

شكل r. نقشه فراوانى خشكسالى بسيار شديد در استان

(رنكى در نسخه الكترونيكى)

1

نقثه فراوانى خثكسالى شديد
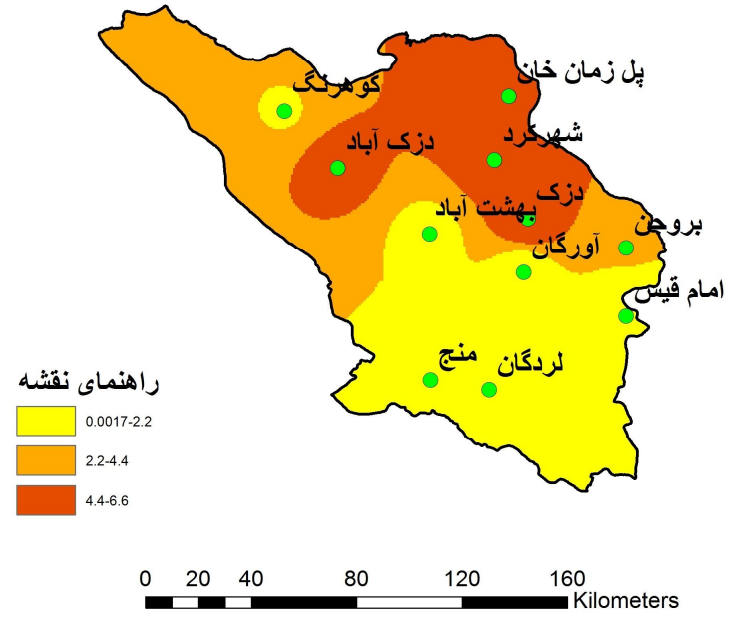

شكل ه ه نقشه فراوانى خشكسالى شديد در استان

(رنكى در نسخه الكترونيكى)

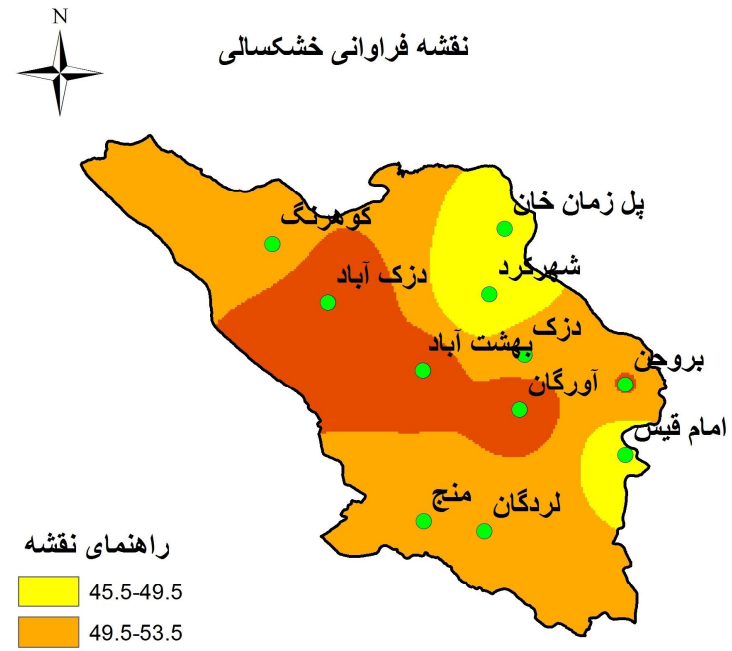

$53.5-57.5$

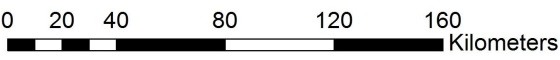

شكل Y. نقشه فراوانى خشكسالى در استان

(رنكى در نسخه الكترونيكى)

نقشه فراوانى خثكسالى منوسط

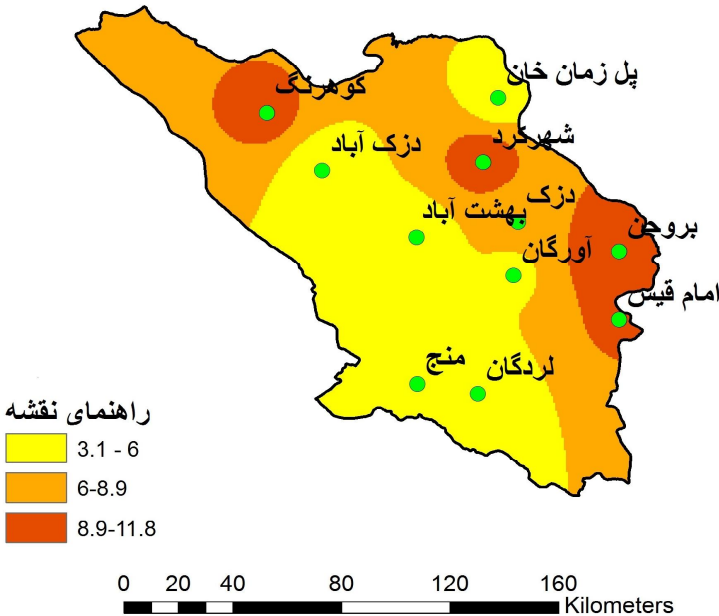

شكل f. نقشه فراوانى خشكسالى متوسط در استان

(رنكى در نسخه الكترونيكى) 


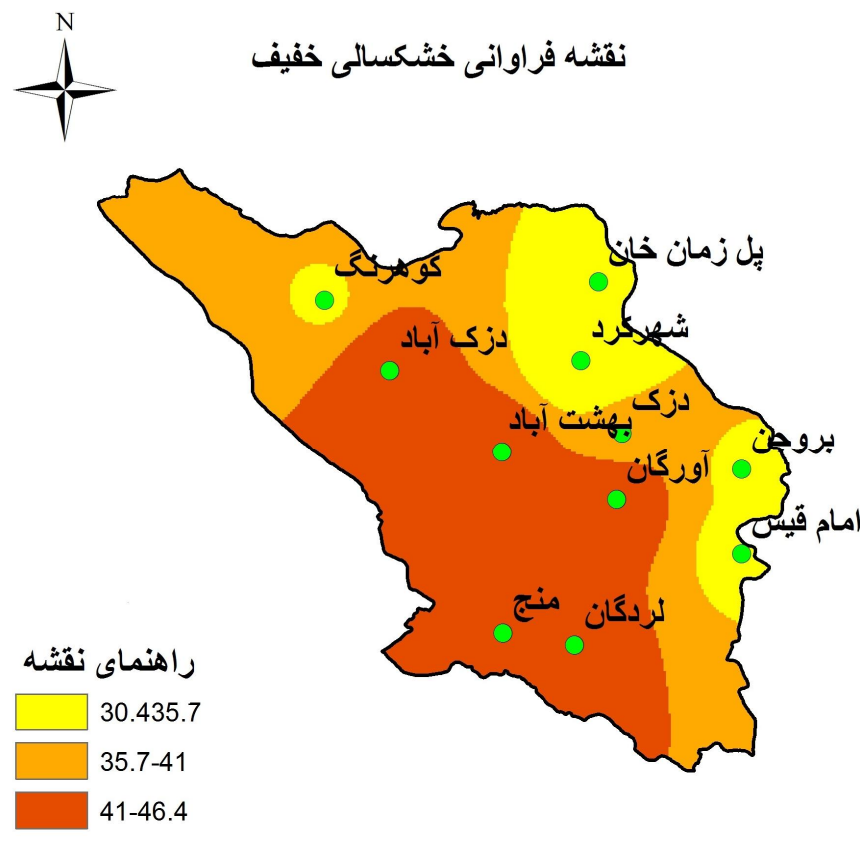

\begin{tabular}{llllll}
0 & 20 & 40 & 80 & 120 & 160 \\
\hline & & &
\end{tabular}

شكل 9. نقشه فروانى خشكسالى خفيف در استان (رنكى در نسخه الكترونيكى)

خشكسالى اين استان با شاخص SPI برداختـه و نتسايج نشـان

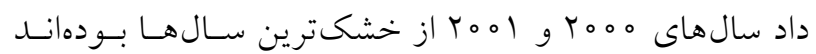

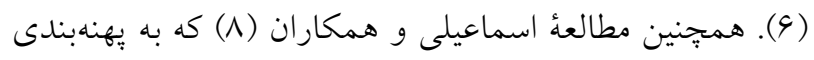

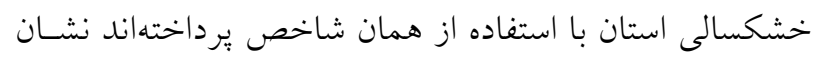

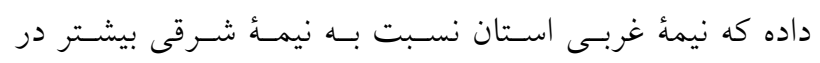

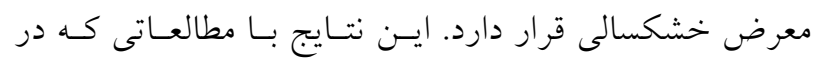

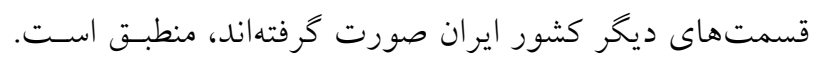

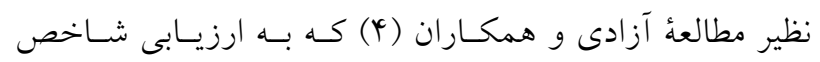

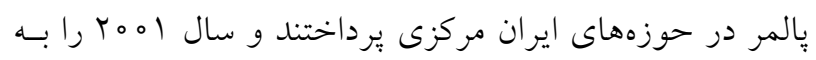

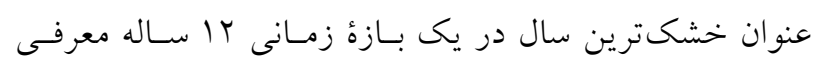

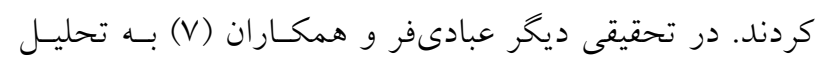

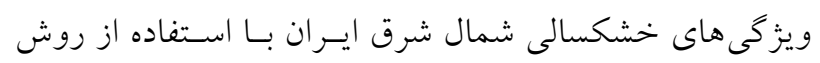

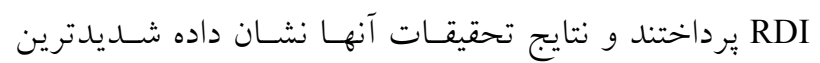

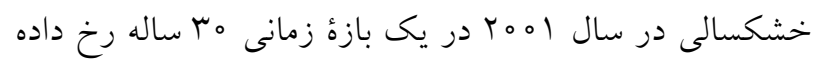

و متوسط قرار گرفته است. با توجه به نقشههاى بهدست آمـده

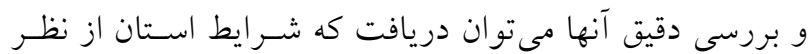

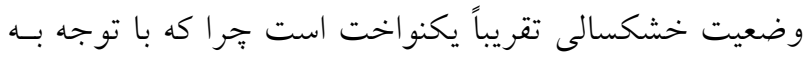

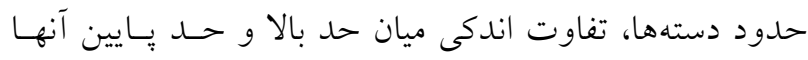

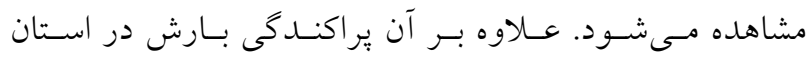

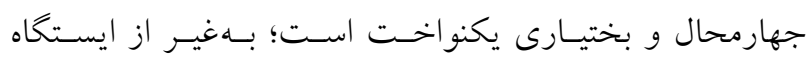
كوهرنخ كه بيشترين ميزان بارندگى را در استان دارد، و نتايج نشان مى دهد كه اين ايستخاه تحت تأثير خشكسالى هاى بسيار

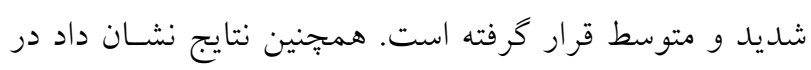

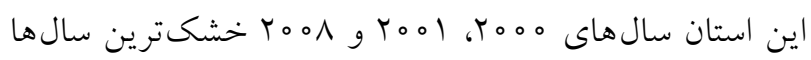

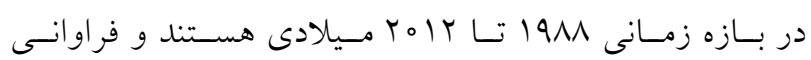
خشكسالى بهطور كلى در نيمه غربى استان بيشتر مشاهده شد.

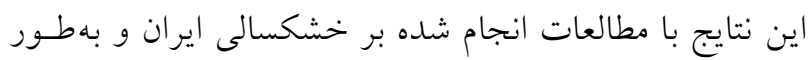

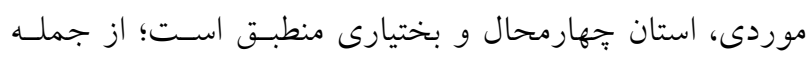

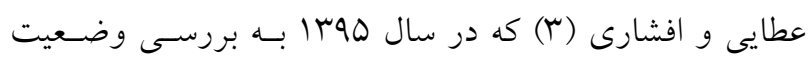


1 . Abramowitz, M. and I. A. Stegun. 1965. Handbook of Mathematical Functions,with Formulas, Graphs, and Mathematical Tables. Dover Publications: New York, U.S.

2. Alley, W. M. 1984. The Palmer drought severity index: limitations and assumptions. Journal of Climate and Applied Meteorology 23(7): 1100-1109.

3. Ataie, H. and M. Afshari. 2016. Analysis of monitoring and spatial distribution of drought in Chaharmahal and Bakhtiari province based on SPI drought index. The Second National Congress on the Development of Agricultural Sciences and Natural Resources. Golestan. Iran. (In Farsi).

4. Azadi, S. 2013. Evaluation of Palmer drought severity index in central Iran. Master thesis, Isfahan University of Tecnology, Isfahan, IR.Iran. (In Farsi).

5. Cook, E. R., D. M. Meko, D. W. Stahle and M. K. Cleaveland. 1999. Drought reconstructions for the continental United States. Journal of Climate 12(4): 1145-1162.

6. Dai, A., K. E. Trenberth and T. Qian . 2004. A global data set of Palmer Drought Severity Index for 1870-2002: relationship with soil moisture and effects of surface warming. Journal of Hydrometeorology $5: 1117-1130$.

7. Ebadi Far, M., T. FathollahZade and S. Mirmanavi. 2016. An analysis of drought characteristics in northeastern Iran by RDI method. Tehran. Iran. (In Farsi).

8. Esmaeeli, K., M. Khodagholi and Y. Toluie. 2015. Drought moitoring of Chaharmahal and Bakhtiari provience with SPI in GIS. International Conference on Geography and Sustainable Development. Tehran. Iran. (In Farsi).

9. Hejazizadeh, Z. and S. Javizadeh. 2010. Introduction to Drought and its Indices. The Organization for Researching and Composing University Textbooks in the Humanities (SAMT). Tehran. (In Farsi).

10. Ma, M., L. Ren, F. Yuan, Sh. Jiang, Y. Liu, H. Kong and L. Gong . 2013. A new standardized Palmer drought index for hydro-meteorological use. Hydrological Processes 28: 5645-5661.

11. Mckee, T. B., N. J. Doesken and J. Kleist. 1993. Drought monitoring with multiple timescales. In: $8^{\text {th }}$ Conference on Applied Climatology, Preprints 179-184.

12. Moghaddasi, M., S. Morid, H. Ghaemi and J. M. V Samani. 2005. Daily drought monitoring, Tehran Province. Iranian Journal of Agriculture of Science 36(1): 51-62. (In Farsi).

13. Omidvar, Sh., L. Sedghi, Gh. Fatahi Nafchi, M. Keyhani and A. Nazemi Harandi. 2012. The Knowledge of Chaharmahal and Bakhtiari Province. Iran Textbook Publishing Company. Tehran. (In Farsi).

14. Palmer, W.C.1965. Meteorologic Drought. US Department of Commerce.Washington, D.C.

15. Vicente-Serrano, S. M., S. Begueria and J. Lopez-Moreno. 2010. A multiscalar drought index sensitive to global warming: the standardized precipitation evapotranspiration index. Journal of Climate 23(7): 1696-1718.

16. Wells, N., S. Goddard and M. J Hayes. 2004. A self-calibrating Palmer Drought Severity Index. Journal of Climate 17: 2335-2351.

17. Wells, N. 2003. PDSI Users Manual, Version 2,0. University of Nebraska-Lincoln.

18. https://www.nrcs.usda.gov 


\title{
Evaluation of New Drought Index of SPDI (Standardized Palmer Drought Index) in Chaharmahal-Va-Bakhtiari Province
}

\author{
F. Saniesales*, S. Soltani and R. Modarres ${ }^{1}$
}

(Received: April 2-2017; Accepted: November 12-2017)

\begin{abstract}
Several indices are used for drought identification and quantification. In this paper, the new Standardized Palmer Drought index (SPDI) was introduced and then the drought condition of Chaharmahal-Va-Bakhtiari Province was studied using this index. For this study, 11 synoptic, climatology, and evaporation meteorology stations were selected. Essential information in this investigation includes monthly temperature, monthly precipitation, and soil moisture measurement. To estimate SPDI, moisture departure, was first calculated on a monthly time scale. Then, converted to cumulative moisture departure values in different time scales including 3, 6, 9, 12, and 24 months. The best statistical distribution $(\mathrm{GEV})$ was then fitted to cumulative departure. These values were then standardized to have the SPDI. The results showed that, as soil moisture affects SPDI estimation, it will be more valid for analyzing and monitoring drought conditions, especially for agricultural drought. Also, the results showed that 2000, 2001, and 2008 years were the driest time in this Province from 1988 to 2012. Moreover, drought frequency was found out in the western half of the Province more than in the other parts.
\end{abstract}

Keywords: Standardized Palmer Drought Index, Drought monitoring, Standardized Precipitation Index, Soil moisture, Chaharmahal-Va-Bakhtiari Province

1. Department of Range and Watershed Management, Faculty of Natural Resources, Isfahan University of Technology, Isfahan, Iran.

Corresponding author, Email: Sanie_farnoosh@yahoo.com 